\title{
AVALIAÇÃO FORMATIVA EM MATEMÁTICA E O TRABALHO DO PROFESSOR DO ENSINO FUNDAMENTAL II FRENTE AOS DESAFIOS DE APRENDIZAGEM
}

Maria Eugênia Lopes Serrano, Célia Maria Guimarães

Universidade Estadual Paulista-UNESP

\section{RESUMO}

$\mathrm{O}$ artigo foi elaborado a partir do resultado de estudo vinculado ao curso de Pedagogia UNESPUNIVESP, que propôs uma discussão em torno das práticas avaliativas dos professores e os fatores que a influenciam, reflexões sobre o papel fundamental da avaliação formativa no processo ensino aprendizagem da disciplina de matemática nos anos finais do ensino fundamental. Confrontou as diretrizes para avaliação da Secretaria da Educação do Estado de São Paulo e as principais ideias dos autores que pesquisam e discutem sobre a avaliação escolar como parâmetros para interpretar e compreender a problemática em torno da avaliação frente aos desafios da aprendizagem dos alunos e o trabalho do professor frente aos desafios da aprendizagem. Discutiu como a avaliação está relacionada a uma concepção de homem e sociedade que queremos formar, percebendo desse modo a existência de uma distância entre o discurso e a prática em função da alienação social (VASCONCELOS, 2010).Traz uma reflexão sobre a importância da avaliação formativa para compreender o contexto escolar de hoje, o currículo e as leis vigentes que regem o trabalho do professor dentro de uma perspectiva de escola.

Palavras-chave: Ensino fundamental. Avaliação Formativa. Matemática. Ensino e Aprendizagem.

\section{INTRODUÇÃO}

Há uma problemática em torno da avaliação escolar, em especial as avaliações na disciplina de matemática. As práticas avaliativas dos professores de matemática e das demais áreas do conhecimento são na sua maioria reprodução de suas experiências como alunos e como educadores, sem que, muitas vezes, estes reflitam sobre uma prática focada no processo de aprendizagem dos alunos. Segundo Vasconcelos (2010), para colaborar com o processo da transformação da realidade da avaliação escolar, é necessário buscar procedimentos na metodologia de trabalho em uma perspectiva dialético-libertadora e que deve compreender: partir da prática, refletir sobre a prática e transformar a prática. O estudo organizado por meio da pesquisa documental e bibliográfica possibilitou interpretar os resultados mais significativos, as anotações mais relevantes e as reflexões pessoais em torno das principais ideias defendidas sobre a importância da Avaliação Formativa em Matemática e o trabalho do professor frente aos desafios de aprendizagem. 


\section{Concepções de avaliação e as práticas avaliativas dos professores.}

Nossa cultura de avaliação está relacionada diretamente a provas e notas; aprovação ou reprovação. Enquanto alunos e professores acreditarem na avaliação, como simples expressão de uma nota, ela continuará exercendo seu papel excludente. Para Luckesi (2001), os instrumentos que usamos: testes, questionários, provas, fichas de observação, etc., não são instrumentos de avaliação, mas de coleta de dados para a avaliação. Ao longo da história percebemos que a avaliação tornou-se uma ferramenta tão poderosa nas mãos dos professores e contrária à promoção humana dos alunos. O que vemos na prática dos professores não é avaliação, mudamos a denominação, mas não a ação. O professor acredita em suas concepções para avaliar e utiliza, dos mais diferentes instrumentos para "medir" os conhecimentos dos alunos, nomeadamente a prova é o mais significativo. Sua presença é justificada por uma exigência social. Sem perceber nossa prática contribui para intensificar, mesmo que inconscientemente as diferenças. Mudar o modo como hoje vemos a avaliação é antes de tudo uma mudança de paradigmas, que deve estar vinculada ao projeto político pedagógico da escola e ao plano de trabalho do professor visando sempre à efetiva aprendizagem de seus alunos. Focamos tanto nas dificuldades dos alunos, que nos esquecemos de valorizar conhecimentos já adquiridos e suas experiências.

A escola que idealizamos instiga, mobiliza, desperta a vontade de aprender no aluno para que consiga significar. Não é possível tornar essa educação dinâmica e interessante sem que se passe pelo ato de avaliar, como um feedback a prática do professor, ao processo de aprender e a auto avaliação do aluno. No contexto escolar, podemos destacar a disciplina curricular de matemática e como ela ao longo dos anos tem contribuído para classificar os alunos, aprovar e reprovar. É preciso entender a matemática, muito mais do que seus conceitos e abstrações, como algo inatingível e onde poucos conseguem transitar. "A matemática precisa estar ao alcance de todos e a democratização do seu ensino deve ser meta prioritária do trabalho docente" (BRASIL, 2001, p.19), o aluno pode compreender e transformar sua realidade por meio do conhecimento matemático, não apresentada como pronta e sim cheia de significação, possibilitando o desenvolvimento cognitivo, do raciocínio lógico dedutivo e sua aplicabilidade. A avaliação está entre o ensinar e o aprender. "O processo de ensino deve dialogar com o de aprendizagem" (WEISZ, 2009, p.65). Nesse diálogo contínuo a avaliação serve para verificar como os alunos estão aprendendo e, também, se o trabalho do professor está alcançado resultados esperados. Para atingir tais objetivos, a escola e os professores precisam definir a função da avaliação, para que, como e quando na organização do trabalho individual e coletivo, para atingir objetivos propostos e 
convergir para um mesmo ponto, a saber, a aprendizagem do aluno, ou seja, uma educação inclusiva e de qualidade.

Se analisarmos as leis que regem as políticas educacionais do País e do Estado identificamos que se estabelece a necessidade de um padrão de qualidade e a Educação Básica é foco principal das políticas educacionais. Os anos finais do Ensino Fundamental da Educação Básica, de acordo com artigo 22 da LDBEN/96, “[...] tem por finalidade desenvolver o educando, assegurar-lhe a formação comum indispensável para o exercício da cidadania e fornecer-lhes meios para progredir no trabalho e em estudos posteriores. Da mesma maneira os PCN (Brasil, 1997, p.33) "apresentam a necessidade de uma proposta educacional que tenha em vista a qualidade da formação a serem oferecidas a todos os estudantes". É preciso considerar em todo o processo, que os conteúdos conceituais, procedimentais e atitudinais são compreendidos e reconhecidos como fundamentais em qualquer etapa da trajetória escolar do aluno. A expectativa do professor quando o aluno chega ao 60 ano é que ele esteja preparado para dar continuidade aos estudos e o aluno acredita que terá de seus professores a mesma atenção de que ainda necessita. O aluno encontra-se diante de um número bem maior de professores, busca um acompanhamento mais próximo do professor, sente-se inseguro e com defasagens em sua aprendizagem. A atuação efetiva do professor nesse trabalho deve possibilitar a participação do aluno na construção do seu conhecimento, considerando seus conhecimentos prévios, em especial os referentes aos desenvolvidos nos anos iniciais, relacionar os problemas de seu cotidiano para exploração da matemática, na resolução de problemas e articular as diferentes áreas do conhecimento, dando desta forma maior significação a sua aprendizagem.

A avaliação exige transparência, para que ela cumpra seu papel, por isso como mediador da aprendizagem dos alunos o professor, deve deixar claro, os diferentes instrumentos utilizados e sua função, para os alunos e pais. Uma vez aprendido, o aluno adquiri conhecimento, sem precisar recorrer ao esforço de memorização para a realização da prova. Da mesma forma professores precisam repensar até que ponto a "prova" está atendendo a escola que hoje temos; sua função e significação. Para MACIEL (2003), não há nada mais cruel do que o aluno escolher uma profissão que exija conhecimentos que não aprendeu. Sabemos bem as consequências da avaliação em nossa trajetória escolar e enxergamos claramente ainda hoje na vida de nossos alunos. $O$ professor acredita que a progressão continuada é a grande causa do déficit de aprendizagem, porém reprovar não garante aprendizagem, apenas estamos punindo. É preciso buscar estratégias 
que motivem o aluno a aprender, mas também o professor a compreender em uma perspectiva processual, em uma prática reflexiva que transforme e crie novas possibilidades.

\section{Avaliação Formativa e sua importância no ensino de matemática dos anos finais do ensino}

\section{fundamental}

A educação possui bons profissionais, que se destacam pela sua pratica pedagógica com resultados que superam as expectativas, mas também temos professores alienados às políticas educacionais e desarticulados do Projeto Político Pedagógico da escola. . Esperamos mudanças. Como diz Paulo Freire (2004, p.47), "saber que ensinar não é transferir conhecimento, mas criar possibilidades para sua própria produção ou a sua construção". A avaliação formativa está muito distante da realidade das salas de aula, pois a mais praticada pelos professores é a avaliação somativa, que tem a função de ao final de uma etapa, verificar se os alunos adquiriram o conhecimento e desenvolveram as habilidades propostas inicialmente. Precisamos recolocar a avaliação no seu lugar: avaliação como processo. Sabemos que o processo leva tempo, pois mudar práticas tão enraizadas exige reflexão e avaliação sobre sua própria atuação docente. O papel do professor é essencial na transição do aluno que conclui o ensino fundamental I e está

iniciando uma nova fase escolar, o ensino fundamental II. É preciso entender como os alunos aprendem, de que maneira atuar no processo de ensino e aprendizagem. Os alunos nos anos iniciais, do EF, apreciam a matemática, pois de maneira lúdica o professor consegue desenvolver no aluno habilidades e competências que lhe permitem entender a matemática muito próxima do seu cotidiano. Em contrapartida, quando os alunos iniciam uma nova trajetória escolar, o EF dos anos finais, a matemática passa então a ser uma disciplina que somente "gênios" são capazes de aprender, inacessível e um termômetro para medir bons alunos. O professor de matemática muitas vezes acha que para que o aluno aprenda é necessário um atendimento diferenciado, mas na verdade "O ensino diferenciado não significa necessariamente que ele seja individualizado, mas, sim, uma intervenção pedagógica que busque a compreensão das diferenças" (MACIEL, 2003, p.55). Exige então do professor um modelo avaliativo que atenda a essa perspectiva. A avaliação formativa atende a essas perspectivas.

A matemática pode ser envolvente quando tratada de maneira mais lúdica, mas também interessante quando entendemos sua magnitude e complexidade relacionada ao nosso cotidiano. Muito mais do que abstrações a matemática possibilita o desenvolvimento cognitivo, afetivo, intelectual e social. A matemática possui uma epistemologia muito própria. Os "erros" tornam-se 
então um referencial avaliativo que possibilita professores e alunos analisarem sobre uma perspectiva de possibilidades de reflexões de ambos, de intervenção por parte do professor e compreensão do aluno na sua responsabilidade com o erro, para uma tomada de decisão. Para Cappelletti (2007) em uma organização em ciclos, com progressão continuada, a avaliação formativa parece ser mais adequada, mas torná-la efetiva não é tarefa fácil. Não há um modelo, mas pistas como as apontadas por HADJI (2001), para ele a avaliação só é formativa se for informativa e responder a perguntas. Ela também deve ser um dialogo interno alimentado pela linguagem do outro.

A avaliação formativa como instrumento regulador da aprendizagem matemática. pode indicar caminhos frente às dificuldades de aprendizagem dos alunos, retomando alguns aspectos já apresentados: diagnosticar, identificando as dificuldades e compreendendo como o aluno aprende, para uma tomada de decisão. No caso da matemática a resolução de problemas tem sido apontada como uma estratégia que envolve os diferentes aspectos a serem estimulados para o desenvolvimento cognitivo dos alunos; o professor ter a flexibilidade para adequar no sentido de auxiliar o aluno a aprender e regular o seu desenvolvimento, envolvendo os alunos no processo de aprendizagem, dando-lhe condições para estimular processos cognitivos, interagir com os outros e intervir para uma aprendizagem formativa; compreender os erros para criar as condições para sua superação, o professor deve levar o aluno a sua autoavaliação; ter prudência, construir um contrato social com clareza, refletir previamente, desconfiar do que parece óbvio, evidenciar valores para tomada de decisão com transparência. Na matemática os erros são pouco discutidos, na sua maioria são apenas apresentados como erro e corrigidos; a avaliação formativa acontece continuamente no processo.

Avaliação formativa pode contribuir para atuação efetiva do professor, como mediador da aprendizagem dos alunos e superação de suas dificuldades de aprendizagem, se tornando uma ferramenta que privilegia o aprender e a inclusão. $\mathrm{O}$ ensino da matemática deve favorecer e possibilitar ao aluno contribuir para o desenvolvimento da sociedade onde ele está inserido.

\section{CONCLUSÃO}

Concluímos que as praticas avaliativas utilizadas pelos professores são evidenciadas por provas e testes que se refletem na trajetória escolar do aluno, excluindo, punindo e classificando. Valorizamos demasiadamente as notas, sem considerar o processo de aprendizagem. A 
matemática em especial há muito tempo é referencial de "bons" e "maus" alunos, sendo motivo de orgulho para professores e de desespero para os pais.

Quando os alunos chegam ao ensino fundamental II se deparam com situações muito diferentes e são, muitas vezes, desmotivados diante das dificuldades encontradas frente aos novos desafios.

Os documentos e as leis que regem as políticas educacionais do País e do Estado de São Paulo fazem inferências essências às práticas avaliativas de modo que se privilegie a aprendizagem dos alunos. A avaliação formativa se apresenta como uma alternativa positiva ao processo de ensino e aprendizagem matemática e ao enfrentamento dos desafios das dificuldades apresentadas pelos alunos. Uma avaliação transformadora que exige práticas pedagógicas que valorizem o processo contínuo, do ensinar e aprender, onde a avaliação é compreendida como instrumento de regulação. A avaliação formativa ainda é uma prática que está sendo construída e que vem ao encontro do que se espera e entende-se por progressão continuada.

\section{REFERÊNCIAS}

BRASIL, LDB. Lei 9394/96. Lei de Diretrizes e Bases da Educação Nacional. Disponível em< www.mec.gov.br>.//acesso em 25/11/2011.

BRASIL. Secretaria de Educação Fundamental. Parâmetros curriculares nacionais: introdução aos parâmetros curriculares nacionais / Secretaria de Educação Fundamental. - Brasília: MEC/SEF, 1997.

CAPPELLETTI, I. F.. Avaliação da aprendizagem: discussão de caminhos. São Paulo: Editora Articulação Universidade/Escola, 2007.

FREIRE, P. Pedagogia da autonomia: saberes necessários à prática educativa. 21. ed. São Paulo: Paz e Terra, 2004.

HADJI, C. A avaliação desmitificada. Porto Alegre: Artmed, 2001.

HOFFMANN, J. Avaliação- mito e desafio: uma perspectiva construtivista. 35. Ed. Porto Alegre: Mediação, 2005.

LUCKESI, C. C. Avaliação da Aprendizagem escolar: estudos e proposições -20. ed.-São Paulo: Cortez, 2009.

LUCKESI, C. C. Entrevista à revista nova escola sobre avaliação da aprendizagem. Disponível em< www.luckesi.com.br .// acesso em 20/12/2012. 
MACIEL, D. M.A avaliação no processo ensino-aprendizagem de matemática, no ensino médio: uma abordagem sócio-cognitivista - 2003. Tese (Mestrado em Educação) - Faculdade de Educação, Universidade Estadual de Campinas, Campinas.

SÃO PAULO. Secretaria de Estado da Educação de São Paulo. Gestão do Currículo na Escola/Secretaria da Educação: São Paulo: SEE. 2008.

VASCONCELOS, C. dos S. Avaliação: concepção dialética-libertadora do processo de avaliação escolar, 19ạ ed. Libertad. São Paulo: (Cadernos Pedagógicos do Libertad), 2010. v.3.

WEISZ, T. O diálogo entre o ensino e a aprendizagem. 2. ed. São Paulo: Ática, 2009. 